\title{
Health Literacy, Cognition and Urinary Incontinence Among Geriatric Inpatients Discharged to Skilled Nursing Facilities
}

\author{
Joshua A. Cohn, Avantika S. Shah, Kathryn M. Goggins, Sandra F. Simmons, Sunil \\ Kripalani, Roger R. Dmochowski, John F. Schnelle, and W. Stuart Reynolds
}

\begin{abstract}
Aims-To investigate the association between health literacy and cognition and nursing and patient-reported incontinence in a geriatric inpatient population transitioning to skilled nursing facilities (SNF).
\end{abstract}

Methods-Health literacy, depression and cognition were assessed via the Brief Health Literacy Screen (BHLS), Geriatric Depression Scale 5-item (GDS) and Brief Interview for Mental Status (BIMS), respectively. Multivariable logistic regression assessed the association between BHLS score and incontinence by: 1) nursing-reported urinary incontinence during hospitalization and 2) patient self-reported "bladder accidents" in the post-enrollment study interview.

Results-1556 hospitalized patients aged 65 and older met inclusion criteria, of whom 922 (59.3\%) were women and 1480 had available BHLS scores. 464 (29.8\%) and $515(33.1 \%)$ patients had nursing-reported and self-reported urinary incontinence, respectively. Nursing-reported incontinence was significantly associated with lower BHLS (i.e. poorer health literacy) (aOR 0.93, 95\% CI 0.89-0.99) and BIMS (i.e. poorer cognition) (aOR 0.90, 95\% CI 0.83-0.97) scores and need for assistance with toileting (aOR 7.08, 95\% CI 2.16-23.21). Patient-reported incontinence was significantly associated with female sex (aOR 1.62, 95\% CI 1.19-2.21), increased GDS score (i.e. greater likelihood of depression) (aOR 1.22, 95\% CI 1.10-1.36) and need for assistance with toileting (aOR 2.46, 95\% CI 1.26-4.79).

Conclusions-Poorer health literacy and cognition are independently associated with an increased likelihood of nursing-reported urinary incontinence among geriatric inpatients transitioning to SNF. Practitioners should consider assessment of health literacy and cognition in frail patients at risk for urinary incontinence and that patient and nursing assessment may be required to capture the diagnosis.

\section{Keywords}

incontinence; geriatrics; health literacy; cognition; depression; elderly; frailty

Corresponding Author: Joshua A. Cohn, Department of Urologic Surgery, 1302A Medical Center North, Nashville, TN 37232-2765, 615.343.5602, 615.322.8990, joshua.cohn@ vanderbilt.edu. 


\section{Introduction}

Older age, poorer health, decreased functional status, dementia and obesity have all been associated with an increased risk of urinary incontinence. ${ }^{1-4}$ These conditions are especially common among hospitalized older adults, who are frequently also burdened by dementia and acute exacerbation of underlying comorbid disease resulting in hospitalization. The International Continence Society strongly encourages assessment of urinary incontinence in at risk older individuals. ${ }^{5}$ However, patient understanding of incontinence is generally poor among both men ${ }^{6}$ and women, ${ }^{7}$ particularly when health literacy is low, increasing the potential for under or misdiagnosis. ${ }^{8,9}$ Data regarding the association between health literacy and cognition and the presence of urinary incontinence in older adults is limited but would be especially relevant in the highly susceptible population of debilitated geriatric inpatients. Therefore, we aimed to assess the association between health literacy and cognition and urinary incontinence among a population of geriatric inpatients transitioning to a skilled nursing facility (SNF).

\section{Materials and Methods}

\section{Participants \& Setting}

This study utilized data collected as part a larger Centers for Medicare and Medicaid Services (CMS) Healthcare Innovations Award (HCIA)-funded study aimed at reducing hospital readmissions and healthcare utilization costs and improving quality of care for geriatric patients transitioning to a SNF. Inherent to the intervention was a prospective assessment of geriatric syndromes among geriatric inpatients at a single large university hospital transitioning to a participating SNF. The university-affiliated Institutional Review Board waived the requirement for written, informed consent. Instead, eligible patients were provided a standardized description of the project by trained research personnel and had the right to refuse the interview.

\section{Assessment of Urinary Incontinence, Health Literacy, and Risk Factors}

The medical record of each participant was reviewed for demographic information and length of hospital stay. Urinary incontinence was assessed by two measures: 1) nursingreported and/or documented incontinence during the course of hospitalization and 2) a patient answering yes or no to the following question administered by study personnel: "Do you have urine or bowel accidents? If yes, which? Bladder, bowel, or both." Subjects were classified as having patient-reported urinary incontinence if they reported incontinence of either urine or urine and bowel. Patients with indwelling catheters on admission or anuria were excluded from the continence assessment and subsequent analyses. Patients were categorized as requiring assistance with toileting if the nurses answered "no" to the question "Can the patient get to the bathroom safely without assistance" or the patients answered "yes" to the question "Do you want to be assisted to the toilet by a nurse every $2-3$ hours?"

Health literacy was assessed using the Brief Health Literacy Screen (BHLS), a validated 3 question, 5-point Likert scale instrument routinely administered by acute care nursing at the time of hospital admission. ${ }^{10}$ Higher scores indicate greater health literacy, with a maximum 
score of 15 and minimum score of 3 . Years of education are also routinely assessed by acute care nursing at the time of hospital admission. Standardized geriatric screening assessments included the Brief Confusion Assessment Method (BCAM), ${ }^{11}$ Brief Interview for Mental Status (BIMS), ${ }^{12}$ and Geriatric Depression Scale (GDS) 5 -item version, ${ }^{13}$ respectively. These assessments represent validated short-form screening tools for the presence of delirium (BCAM), cognitive impairment (BIMS), and depression (GDS 5-item). BIMS assessments were not included for patients who had missing BCAM scores or scored positively for delirium on the BCAM as the presence of delirium can itself result in the presence of cognitive dysfunction due to a variety of causes not attributed to dementia. ${ }^{14}$ The scaling and justification for use of these instruments have been previously described. ${ }^{14}$

\section{Statistical Analysis}

Descriptive statistics included means and standard deviations for continuous variables and proportions for categorical variables. Mann-Whitney $\mathrm{U}$ and Chi square tests were used for the comparison of continuous and categorical variables, respectively. Multivariable logistic regression controlling for age, sex, years of education, race/ethnicity (Caucasian versus NonCaucasian), BIMS total score, GDS total score and need for assistance with toileting was performed to determine the association between BHLS total score and the presence of urinary incontinence according to nurse and patient reports. Separate regression analyses were performed for both nursing-reported incontinence and patient-reported incontinence. Patients without valid incontinence, BHLS, BIMS and GDS scores were excluded from the regression analysis. Additionally, we studied the agreement between nursing-reported and patient-reported incontinence using the Kappa measure of agreement. Statistical significance was considered for two sided $p$-values $<0.05$. All analyses were performed using IBM SPSS Statistics for Windows, Version 24.

\section{Results}

\section{Study Population}

Between the time of study initiation in January 2013 and April 2015,1556 patients were enrolled in the larger CMS-funded study, from which the data for the current study was drawn. Demographic data is provided in Table 1. Mean age of the study population was 75.3 \pm 11.4 years; $59.2 \%$ were female and $83.6 \%$ Caucasian. Approximately two-thirds (63.6\%) were admitted to a medical service, and mean length of stay was $8.3 \pm 5.9$ days. Mean years of education was 13.2 \pm 3.7 , mean BHLS score $10.1 \pm 3.7$ and $292(26.5 \%)$ subjects demonstrated cognitive impairment on BIMS. The vast majority (94.0\%) of participants required assistance with toileting.

\section{Nurse and Patient Reports of Urinary Incontinence}

A total of 464 (29.8\%) subjects had nursing-reported urinary incontinence, and 515 (33.1\%) participants reported having "bladder accidents". Nursing-reported or patient-reported continence data was unavailable or not applicable (i.e., urinary catheter) in 18.8\% (295) of patients. 
1203 patients met inclusion criteria for the analysis of nursing-reported urinary incontinence, of whom 436 (36.2\%) had nursing-reported urinary incontinence (Table 2). Incontinence was reported in 34.8\% (161/462) and 37.1\% (275/741) of men and women, respectively. Patients with nursing-reported urinary incontinence were significantly older, more likely to require assistance with toileting, have fewer total years of education and have higher GDS and lower BIMS and BHLS scores relative to continent patients according to nurse report. On multivariable logistic regression analyses, a lower BHLS score (i.e., poorer health literacy) was independently associated with increased odds of nursing-reported urinary incontinence (OR $0.93,95 \% \mathrm{CI} 0.89-0.99 ; \mathrm{p}=0.012$ ), as were a patient's need for assistance with toileting (OR 7.08, 95\% CI 2.16-23.21) and a lower BIMS score (i.e., more cognitively impaired) (OR 0.90, 95\% CI 0.83-0.97) (Table 3).

1209 patients met inclusion criteria for the analysis of patient-reported urinary incontinence (Table 2), of whom 491 (40.6\%) reported "bladder accidents", including 34.4\% (171/497) of men and $44.9 \%$ (320/712) of women. Patients with self-reported urinary incontinence were significantly older and more likely to be female, require assistance with toileting and have higher GDS and lower BIMS and BHLS scores. Multivariable logistic regression analyses found female sex (OR 1.62, 95\% CI 1.19-2.21), higher GDS total score (indicative of probable depression) (OR 1.22, 95\% CI 1.10-1.63) and the need for assistance with toileting (OR 2.46, 95\% CI 1.26-4.79) to be independently associated with patient-reported urinary incontinence (Table 3). Unlike nursing-reported incontinence, neither health literacy nor cognition was independently associated with patient-reported urinary incontinence.

Nursing and patient-reported incontinence were discordant in 276/1070 (25.8\%) patients with available data for both, including $17.4 \%$ who self-reported having "bladder accidents" but were not incontinent per nursing report and $8.4 \%$ who were incontinent per nursing but did not report "bladder accidents" (Table 4). The Kappa agreement statistic between nursing and patient reports for urinary incontinence was $0.456(\mathrm{p}<0.001)$, which suggests moderate agreement.

\section{Discussion}

In our cohort of hospitalized older adults transitioning to a SNF, poorer health literacy and cognition were independently associated with nursing-reported urinary incontinence during hospitalization. Each 1-point decrease in a patient's BHLS and BIMS total scores was associated with a $7 \%$ and $10 \%$ increase, respectively, in the likelihood of nursing-reported incontinence, and higher GDS total score was an independent risk factor for patient-reported incontinence. The need for toileting assistance was the predominant risk factor, increasing the odds of nursing-reported and patient-reported incontinence by approximately 7 - and 2.5fold, respectively.

The relationship between education, health literacy and cognition is complex. Existing data on the impact of any of these factors on urinary incontinence is mixed, and studies have primarily focused only on education. ${ }^{3,15}$ One exception is a population-wide study in Sweden that evaluated both dementia and education as risk factors for urinary incontinence. ${ }^{16}$ Specifically, the authors reported urinary incontinence rates of nearly $50 \%$ for former 
blue-collar adults versus only $16 \%$ for former white-collar adults older than 75 years. Furthermore, "memory problems" were associated with a 70\% increased likelihood of urinary incontinence (OR 1.70, 95\% CI 1.42-2.03) suggesting, as in the present study, the potentially significant contributions of both dementia and decreased education to the development of urinary incontinence.

Poor health literacy may also markedly impact a patient's ability to understand and/or manage his or her condition or even a healthcare provider's assessment for its presence. ${ }^{17}$ However, the relationship between health literacy and urinary incontinence has received limited study. Health literacy has been demonstrated to decline with age independent of cognitive decline and depression, ${ }^{18}$ supporting a potential independent role for poor health literacy in the presence, diagnosis and management of urinary incontinence, as suggested by our study results.

One possible explanation for an independent association of poor health literacy with urinary incontinence may be a decreased ability to affect lifestyle changes that may limit or avoid leakage episodes. Many patients intuitively enact lifestyle changes such as decreased fluid intake, caffeine avoidance and bathroom awareness in the absence of advice from a healthcare provider. ${ }^{19}$ Patients with poor understanding of their condition may not be able to identify and avoid associated provocative factors, particularly when cognitive and physical decline are concomitantly present. ${ }^{18,20}$

Physician diagnosis and counseling also becomes more difficult when health literacy is poor. Only $15 \%$ of a sample of 109 low-income, inner-city men, $60 \%$ of whom tested at the $8^{\text {th }}$ grade level or below, correctly understood the term "incontinence", with comprehension significantly worse as health literacy declined. ${ }^{8}$ In contrast, in a separate study of 36 women with high health literacy, understanding of urinary incontinence and disease recall was $94 \%$. ${ }^{21}$ Taken together, these studies demonstrate the impact of health literacy on understanding of terms frequently used by healthcare providers. Furthermore, nearly half of surveys in pelvic medicine are written above the eighth grade level, potentially decreasing their utility in both diagnosis and disease monitoring in patients with poorer health literacy. ${ }^{22}$

In the present study, nursing and patient-reported incontinence were discordant in approximately one quarter of patients, for which there are several possible explanations. It is possible that some patients misunderstood the study questions regarding "bladder accidents" and misreported their presence or absence. Temporality may also play a role in reporting between nurses, who are assessing the presence of incontinence during the hospital stay, and patients, who may be reporting on whether incontinence was present prior to hospital admission. In addition, physical decline associated with acute exacerbation of multiple comorbid conditions may lead to new-onset incontinence, which was observed in over onethird of elderly patients with dementia admitted to acute care. ${ }^{23}$ Medical comorbidity from acute or chronic diagnoses such as cerebrovascular accident and diabetes likely increased incontinence risk within our study population due to their direct impact on the lower urinary tract as well as overall functional status. Lastly, a subset of patients with functional incontinence may have avoided incontinence during their hospital stay due to the availability of nursing assistance with toileting. 
The strengths of this study include its prospective nature, at-risk patient population and ability to control for many potential confounders based upon sample size and data inherent to the larger study. In addition, it is the first to assess the association between health literacy and incontinence in the particularly vulnerable population of geriatric inpatients being discharged to SNF. Weaknesses include lack of extensive, validated continence questionnaires documenting continence severity and limited objective measures of incontinence and mobility. Furthermore, given the particularly frail older sample population, our results may not be generalizable to other subsets of hospitalized patients at risk for urinary incontinence.

\section{Conclusions}

Greater education, health literacy, and baseline cognitive abilities may permit resistance to both acute and chronic deterioration of physical health. Declining literacy and cognition inherent to many debilitated elderly patients renders diagnosis and treatment of urinary incontinence especially challenging. Our study suggests that poorer health literacy and cognition may confer increased risk of having urinary incontinence, which may also be associated with an impaired ability to manage the condition or understand healthcare provider assessments for its presence. Practitioners treating vulnerable older populations at risk for urinary incontinence should consider routine assessment of both health literacy and cognitive function in conjunction with direct, specific questions about the patient's experience of bladder accidents.

\section{Acknowledgments}

Funding

This research was supported by the Department of Health and Human Services, Centers for Medicare \& Medicaid Services grant \#1C1CMS331006 awarded to Principal Investigator, John F. Schnelle, PhD. This research was also supported by CTSA award UL1TR000445 from the National Center for Advancing Translational Sciences. The contents of this publication are solely the responsibility of the authors and do not necessarily represent the official views of the U.S. Department of Health and Human Services or any of its agencies, the National Center for Advancing Translation Science, the National Institutes of Health or the Department of Veterans' Affairs.

\section{References}

1. Bresee C, Dubina ED, Khan AA, Sevilla C, Grant D, Eilber KS, Anger JT. Prevalence and correlates of urinary incontinence among older community-dwelling women. Female Pelvic Med Reconstr Surg. 2014; 20(6):328-333. DOI: 10.1097/SPV.0000000000000093 [PubMed: 25185631]

2. Lasserre A, Pelat C, Guéroult V, Hanslik T, Chartier-Kastler E, Blanchon T, Ciofu C, Montefiore ED, Alvarez FP, Bloch J. Urinary Incontinence in French Women: Prevalence, Risk Factors, and Impact on Quality of Life. Eur Urol. 2009; 56(1):177-183. DOI: 10.1016/j.eururo.2009.04.006 [PubMed: 19376639]

3. Khullar V, Sexton CC, Thompson CL, Milsom I, Bitoun CE, Coyne KS. The relationship between BMI and urinary incontinence subgroups: results from EpiLUTS. Neurourol Urodyn. 2014; 33(4): 392-399. DOI: 10.1002/nau.22428 [PubMed: 23780904]

4. Coyne KS, Kvasz M, Ireland AM, Milsom I, Kopp ZS, Chapple CR. Urinary incontinence and its relationship to mental health and health-related quality of life in men and women in Sweden, the United Kingdom, and the United States. Eur Urol. 2012; 61(1):88-95. DOI: 10.1016/j.eururo. 2011.07.049 [PubMed: 21831517] 
5. DuBeau CE, Kuchel GA, Johnson T, Palmer MH, Wagg A. Fourth International Consultation on Incontinence. Incontinence in the frail elderly: report from the 4th International Consultation on Incontinence. Neurourol Urodyn. 2010; 29(1):165-178. DOI: 10.1002/nau.20842 [PubMed: 20025027]

6. Wang R, McGuire EJ, He C, Faerber GJ, Latini JM. Long-term outcomes after primary failures of artificial urinary sphincter implantation. Urology. 2012; 79(4):922-928. DOI: 10.1016/j.urology. 2011.11.051 [PubMed: 22305763]

7. Senekjian L, Heintz K, Egger MJ, Nygaard I. Do Women Understand Urogynecologic Terminology? Female Pelvic Med Reconstr Surg. 2011; 17(5):215-217. DOI: 10.1097/SPV. 0b013e31822dcffe [PubMed: 21984964]

8. Wang DS, Jani AB, Tai CG, Sesay M, Lee DK, Goodman M, Echt KV, Kilbridge KE, Master VA. Severe lack of comprehension of common prostate health terms among low-income inner-city men. Cancer. 2013; 119(17):3204-3211. DOI: 10.1002/cncr.28186 [PubMed: 23733135]

9. Anger JT, Lee UJ, Mittal BM, Pollard ME, Tarnay CM, Maliski S, Rogers RG. Health literacy and disease understanding among aging women with pelvic floor disorders. Female Pelvic Med Reconstr Surg. 2012; 18(6):340-343. DOI: 10.1097/SPV.0b013e31826fb8d3 [PubMed: 23143427]

10. Cawthon C, Mion LC, Willens DE, Roumie CL, Kripalani S. Implementing routine health literacy assessment in hospital and primary care patients. Jt Comm J Qual Patient Saf Jt Comm Resour. 2014; 40(2):68-76.

11. Han JH, Wilson A, Shintani A, Graves AJ, Schnelle JF, Shuster JL, Vernon J, Jones D, Dittus RS, Storrow AB, Ely EW. 76 Validation of the Brief Confusion Assessment Method in Older Emergency Department Patients. Ann Emerg Med. 2012; 60(4):S28-S29. DOI: 10.1016/ j.annemergmed.2012.06.355

12. Chodosh J, Edelen MO, Buchanan JL, Yosef JA, Ouslander JG, Berlowitz DR, Streim JE, Saliba D. Nursing home assessment of cognitive impairment: development and testing of a brief instrument of mental status. J Am Geriatr Soc. 2008; 56(11):2069-2075. DOI: 10.1111/j. 1532-5415.2008.01944.x [PubMed: 19016941]

13. Rinaldi P, Mecocci P, Benedetti C, Ercolani S, Bregnocchi M, Menculini G, Catani M, Senin U, Cherubini A. Validation of the five-item geriatric depression scale in elderly subjects in three different settings. J Am Geriatr Soc. 2003; 51(5):694-698. [PubMed: 12752847]

14. Bell SP, Vasilevskis EE, Saraf AA, Jacobsen JML, Kripalani S, Mixon AS, Schnelle JF, Simmons SF. Geriatric Syndromes in Hospitalized Older Adults Discharged to Skilled Nursing Facilities. J Am Geriatr Soc. 2016; 64(4):715-722. DOI: 10.1111/jgs.14035 [PubMed: 27059831]

15. Gorina Y, Schappert S, Bercovitz A. Prevalence of Incontinence among older Americans. Vital Health Stat. 2014; 3(36) http://www.cdc.gov/nchs/data/series/sr_03/sr03_036.pdf.

16. Stenzelius K, Mattiasson A, Hallberg IR, Westergren A. Symptoms of urinary and faecal incontinence among men and women $75+$ in relations to health complaints and quality of life. Neurourol Urodyn. 2004; 23(3):211-222. DOI: 10.1002/nau.20030 [PubMed: 15098216]

17. McCaffery KJ, Holmes-Rovner M, Smith SK, Rovner D, Nutbeam D, Clayman ML, Kelly-Blake K, Wolf MS, Sheridan SL. Addressing health literacy in patient decision aids. BMC Med Inform Decis Mak. 2013; 13(Suppl 2):S10.doi: 10.1186/1472-6947-13-S2-S10 [PubMed: 24624970]

18. Baker DW, Gazmararian JA, Sudano J, Patterson M. The Association Between Age and Health Literacy Among Elderly Persons. J Gerontol B Psychol Sci Soc Sci. 2000; 55(6):S368-S374. DOI: 10.1093/geronb/55.6.S368 [PubMed: 11078114]

19. Anger JT, Nissim HA, Le TX, Smith AL, Lee U, Sarkisian C, Litwin MS, Raz S, Rodriguez LV, Maliski SL. Women's experience with severe overactive bladder symptoms and treatment: insight revealed from patient focus groups. Neurourol Urodyn. 2011; 30(7):1295-1299. DOI: 10.1002/ nau.21004 [PubMed: 21538495]

20. Huang AJ, Brown JS, Thom DH, Fink HA, Yaffe K. Urinary Incontinence in Older CommunityDwelling Women: The Role of Cognitive and Physical Function Decline. Obstet Gynecol. 2007; 109(4):909-916. DOI: 10.1097/01.AOG.0000258277.01497.4b [PubMed: 17400853]

21. Anger JT, Weinberg AE, Albo ME, Smith AL, Kim J-H, Rodríguez LV, Saigal CS. Trends in surgical management of stress urinary incontinence among female Medicare beneficiaries. Urology. 2009; 74(2):283-287. DOI: 10.1016/j.urology.2009.02.011 [PubMed: 19501886] 
22. Alas AN, Bergman J, Dunivan GC, Rashid R, Morrisroe SN, Rogers RG, Anger JT. Readability of common health-related quality-of-life instruments in female pelvic medicine. Female Pelvic Med Reconstr Surg. 2013; 19(5):293-297. DOI: 10.1097/SPV.0b013e31828ab3e2 [PubMed: 23982579]

23. Furlanetto K, Emond K. "Will I come home incontinent?" A retrospective file review: Incidence of development of incontinence and correlation with length of stay in acute settings for people with dementia or cognitive impairment aged 65 years and over. Collegian. 2016; 23(1):79-86. DOI: 10.1016/j.colegn.2014.09.013 [PubMed: 27188043] 


\section{Table 1}

Baseline Characteristics of the Study Population

\begin{tabular}{lc}
\hline & Overall (N=1556) \\
\hline Age, years & $75.3(11.4)$ \\
Sex & \\
$\quad$ Female & $59.3(922)$ \\
Race & \\
$\quad$ White & $83.6(1301)$ \\
$\quad$ Other & $16.4(255)$ \\
Education, years (N=1349) & $13.2( \pm 3.7)$ \\
Admission Service & \\
$\quad$ Medical & $63.6(990)$ \\
$\quad$ Surgical & $36.4(566)$ \\
Brief Health Literacy Scores (N=1480) & $10.1( \pm 3.7)$ \\
Positive Delirium - Brief Confusion Assessment Method (N=1228) & $8.7(107)$ \\
Cognitively Impaired - Brief Interview Mental Status Scores $\leq \mathbf{1 2}(\mathbf{N}=\mathbf{1 1 0 1})$ & $26.5(292)$ \\
Depressive Symptoms - 5-item Geriatric Depression Scale score $\mathbf{2}(\mathbf{N}=\mathbf{1 1 0 9})$ & $40.7(451)$ \\
Bladder Incontinence (Nurse or Chart) & \\
Incontinent & $29.8(464)$ \\
Continent & $51.3(799)$ \\
Missing or N/A (catheter, dialysis) & $18.8(293)$ \\
Bladder Accidents (Per patient self-report) & \\
$\quad$ Yes & $33.1(515)$ \\
$\quad$ No & $48.0(747)$ \\
$\quad$ Missing or N/A (catheter, dialysis) & $18.9(294)$ \\
Hequires Assistance with Toileting (N=1308) & $94.0(1230)$ \\
\hline & $8.3( \pm 5.9)$ \\
\hline
\end{tabular}

Mean (Standard Deviation) for Continuous measures \& Percent (Frequency) for Categorical measures 
Table 2

Baseline Characteristics by Presence or Absence of Nursing- and Patient-Reported Urinary Incontinence

\begin{tabular}{|c|c|c|c|}
\hline$\underline{\text { Nursing-Reported Urinary Incontinence }}$ & $\begin{array}{l}\text { Bladder Incontinent } \\
\qquad \mathbf{N}=436\end{array}$ & $\begin{array}{l}\text { Bladder Continent } \\
\quad \mathbf{N}=767\end{array}$ & p-value ${ }^{*}$ \\
\hline Age, years; mean $( \pm$ SD) & $77.5(11.5)$ & $75.7(10.9)$ & $<0.001$ \\
\hline Sex $\%(n)$ & & & 0.427 \\
\hline Female & $63.1(275)$ & $60.8(466)$ & \\
\hline Race \% (n) & & & 0.409 \\
\hline White & $82.8(361)$ & $84.6(649)$ & \\
\hline Other & $17.2(75)$ & $15.4(118)$ & \\
\hline Education, years ${ }^{a}$; mean $( \pm \mathrm{SD})$ & $12.9( \pm 3.4)$ & $13.3( \pm 3.9)$ & 0.034 \\
\hline Brief Health Literacy Scores; mean $( \pm \mathrm{SD})$ & $8.8( \pm 3.7)$ & $10.9( \pm 3.4)$ & $<0.001$ \\
\hline Brief Interview Mental Status Score ${ }^{b}$ & $12.2(3.5)$ & $13.6(2.2)$ & $<0.001$ \\
\hline 5-Item Geriatric Depression Scale Score ${ }^{c}$ & $1.7( \pm 1.4)$ & $1.4( \pm 1.4)$ & $<0.001$ \\
\hline Requires assistance with toileting ${ }^{d}$ & $98.7(372)$ & $90.3(596)$ & $<0.001$ \\
\hline Hospital Length of Stay & $8.3(5.9)$ & $7.8(5.3)$ & 0.252 \\
\hline Patient-Reported Urinary Incontinence & $\begin{array}{l}\text { Bladder Accidents } \\
\mathrm{N}=\mathbf{4 9 1}\end{array}$ & $\begin{array}{l}\text { No Bladder Accidents } \\
\quad \mathrm{N}=718\end{array}$ & \\
\hline Age, years; mean $( \pm$ SD) & $76.2( \pm 10.8)$ & $74.4( \pm 11.1)$ & 0.007 \\
\hline Sex $\%(n)$ & & & $<0.001$ \\
\hline Female & $65.2(320)$ & $54.6(392)$ & \\
\hline Race \% (n) & & & 0.239 \\
\hline White & $87.0(427)$ & $84.5(607)$ & \\
\hline Other & $13.0(64)$ & $15.5(111)$ & \\
\hline Education, years ${ }^{e}$; mean $( \pm \mathrm{SD})$ & $13.4( \pm 3.8)$ & $13.4( \pm 3.5)$ & 0.853 \\
\hline Brief Health Literacy Scores; mean $( \pm$ SD) & $10.07( \pm 3.6)$ & $10.7( \pm 3.5)$ & 0.003 \\
\hline Brief Interview Mental Status Score ${ }^{f}$ & $13.1(2.6)$ & $13.4(2.5)$ & 0.031 \\
\hline 5-Item Geriatric Depression Scale Score $g$ & $1.7(1.4)$ & $1.3(1.3)$ & $<0.001$ \\
\hline Requires assistance with toileting $h$ & $96.6(457)$ & $91.7(608)$ & $<0.001$ \\
\hline Hospital Length of Stay & $8.1(5.5)$ & $8.5(8.5)$ & \\
\hline \multicolumn{4}{|c|}{ Mann-Whitney U test for continuous and Chi-Square for Categorical Variables } \\
\hline \multicolumn{4}{|l|}{ Incontinent $\mathrm{N}=397$; Continent $\mathrm{N}=692$} \\
\hline \multicolumn{4}{|l|}{$b_{\text {Incontinent } \mathrm{N}=276 ; \text { Continent } \mathrm{N}=631}$} \\
\hline \multicolumn{4}{|l|}{$c$ Incontinent $\mathrm{N}=274 ;$ Continent $\mathrm{N}=631$} \\
\hline \multicolumn{4}{|l|}{$d_{\text {Incontinent } \mathrm{N}=377 ; \text { Continent } \mathrm{N}=660}$} \\
\hline \multicolumn{4}{|l|}{ 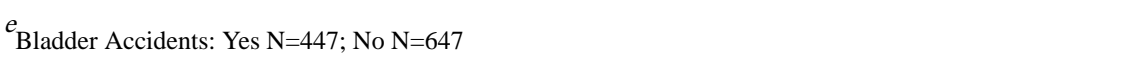 } \\
\hline \multicolumn{4}{|l|}{ 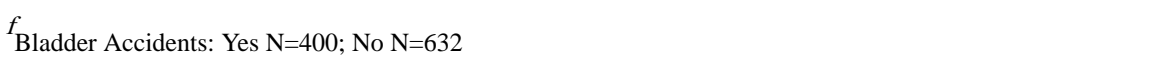 } \\
\hline${ }^{g}$ Bladder Accidents: Yes N=414; No N=641 & & & \\
\hline 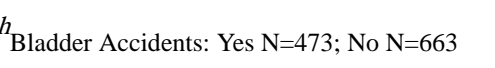 & & & \\
\hline
\end{tabular}


Percentages calculated using valid data as denominator 


\section{Table 3}

Binary Logistic Regression of Health Literacy Predicting Nursing and Patient-reported Urinary Incontinence

\begin{tabular}{|c|c|c|c|c|}
\hline \multicolumn{5}{|c|}{ Nursing-Reported Urinary Incontinence } \\
\hline & \multirow[t]{2}{*}{ Odds Ratio } & \multicolumn{2}{|c|}{ 95\% Confidence Interval } & \multirow[t]{2}{*}{ p-value } \\
\hline & & Lower Limit & Upper Limit & \\
\hline BHLS Score & 0.934 & 0.885 & 0.985 & $0.012^{*}$ \\
\hline Age, years & 1.031 & 0.978 & 1.086 & 0.258 \\
\hline Educations, years & 1.013 & 0.996 & 1.030 & 0.138 \\
\hline Race (Other versus White) & 1.306 & 0.810 & 2.106 & 0.273 \\
\hline Female & 1.208 & 0.839 & 1.740 & 0.311 \\
\hline Requires assistance with toileting & 7.083 & 2.162 & 23.205 & $0.001^{*}$ \\
\hline GDS-5 Score & 1.113 & 0.980 & 1.263 & 0.099 \\
\hline BIMS Score & 0.896 & 0.832 & 0.966 & $0.004^{*}$ \\
\hline \multicolumn{5}{|c|}{ Patient-Reported Urinary Incontinence } \\
\hline & \multirow[t]{2}{*}{ Odds Ratio } & \multicolumn{2}{|c|}{ 95\% Confidence Interval } & p-value \\
\hline & & Lower Limit & Upper Limit & \\
\hline Healthy Literacy Score & 0.994 & 0.949 & 1.041 & 0.802 \\
\hline Age, years & 1.031 & 0.985 & 1.079 & 0.186 \\
\hline Educations, years & 1.011 & 0.997 & 1.026 & 0.114 \\
\hline Race (Other versus White) & 1.040 & 0.685 & 1.580 & 0.854 \\
\hline Female & 1.621 & 1.191 & 2.207 & $0.002^{*}$ \\
\hline Requires assistance with toileting & 2.461 & 1.264 & 4.791 & $0.008^{*}$ \\
\hline GDS-5 Score & 1.223 & 1.096 & 1.364 & $<0.001^{*}$ \\
\hline BIMS Score & 0.973 & 0.910 & 1.039 & 0.408 \\
\hline
\end{tabular}

BHLS—Brief Health Literacy Screen

GDS - Geriatric Depression Scale

BIMS - Brief Interview for Mental Status

*

p-values significant at $<0.05$ 


\section{Table 4}

Comparison between Bladder Incontinence as per Nurse and Patient report [N=1070] ${ }^{*}$

\begin{tabular}{ccccc} 
& & \multicolumn{2}{c}{ PATIENT REPORT } & Total \\
& & Continent & Incontinent & \\
\hline \multirow{2}{*}{ NURSE REPORT } & Continent & $527(49.3)$ & $186(17.4)$ & $713(66.6)$ \\
& Incontinent & $90(8.4)$ & $267(25.0)$ & $357(33.4)$ \\
\hline Total & $617(57.7)$ & $453(42.3)$ & $1070(100.0)$ \\
\hline
\end{tabular}

